Journal of Engineering and Applied Sciences 15 (1): 261-266, 2020

ISSN: 1816-949X

(C) Medwell Journals, 2020

\title{
Comparison of Welding Process SAW and FCAW on ASTM A36
}

\author{
Herman Pratikno and Wimala L. Dhanistha \\ Department of Ocean Engineering, Institute Teknologi Sepuluh Nopember, Surabaya, Indonesia
}

\begin{abstract}
Underwater welding is the most important in the offshore field. Welding method that is often used is the method of welding SAW (Submerged Arc Welding). The use of this welding method due to its low cost, relatively faster process, lighter and more varied form of construction. The SAW welding principle is almost the same on the SMAW (Shielded Metal Arc Welding) welding process but the flux present on the SAW is shaped like sand while in SMAW the electrode is enclosed by flux. In addition to the SAW method normally used in the shipping industry is FCAW (Flux Cored Arc Welding). The use of this welding method is due to its low cost, relatively faster process, uniform welding result and machine used automatically. This welding usually uses an additional protective gas to avoid being contaminated with air around the welding area.
\end{abstract}

Key words: SAW, FCAW, ASTM 36, construction, machine, welding

\section{INTRODUCTION}

Welding is the most important in shipbuilding. Variations of welding refers to Welding Procedure Specification (WPS) in order to obtain good welding results. Welding is often used today is electric arc welding. Welding methods are often used by the shipping industry such as the method of welding welding Submerged Arc Welding (SAW). The use of this welding method due to its low cost, relatively faster process, lighter and more varied form of construction. SAW welding principle is almost the same on Shielded Metal Arc Welding (SMAW) welding process. SMAW is manual welding while SAW is automatic welding. In addition to the SAW method normally used in the shipping industry is Flux Cored Arc Welding (FCAW). The use of this welding method is due to its low cost, relatively faster process, uniform welding result and machine used automatically. FCAW is one type of electric weld that supplies the electrode filler mechanically into the arc formed between the electrode filler tip and the parent metal. This welding usually uses an additional protective gas to avoid being contaminated with air around the welding area. Protective gases generally use $\mathrm{CO}_{2}$ gas or a mixture of $\mathrm{CO}_{2}$ and argon.

The material before being applied must be known to its mechanical properties by conducting tests such as tensile test. This test aims to determine the resistance of a material to the static force given slowly. This tensile test is one of the most important tests to do because with this test it can provide various information about metallic properties. In addition to other test tensile test is the test notch or impact test. This test is performed to determine the tenacity of a material by giving a sudden and rapid burden. Methods in this test there are two namely Charpy and Izod. But the test is often used charpy method. Mechanical test other than tensile test and notch test that is hardness test. Where this test aims to determine the resistance of a material to the load identitor. One of the identities used is the diamond pyramid in which the identitor is present in the Vicker hardness method.

\section{MATERIALS AND METHODS}

Submerged arc welding: Submerged Arc Welding (SAW) is one of the welding process of electric welding type where the material is welded by heating and melting the parent metal and electrode by the electric arc located between the parent metal and electrode. The electrode is a continuously supplied filler metal reel and this welding is granulated as a sandstone granule to protect from outside air contamination. SAW welding principle is almost the same as SMAW but flux is used in the form of sand grain while SMAW elektoda is covered by flux. In addition SAW is an automatic welding while SMAW manual welding. The SAW welding process does not require pressure. The electrode is a continuously supplied filler metal reel and this welding is granulated as a sandstone granule to protect from outside air contamination. The SAW welding principle is almost the same as SMAW but the flux used is sand grain while SMAW elektoda is covered by flux. In addition SAW is an automatic welding while SMAW manual welding.

There are advantages and disadvantages of using SAW method. The advantages of this method can be used to weld various types of structural steel and alloy steel including low carbon steel, low alloy steel, heat-treated steel, high alloy steel such as stainless steel. In addition, because the SAW process is automatic, it is not necessary that high welding skills and changes in welding

Corresponding Author: Herman Pratikno, Department of Ocean Engineering, Institute Teknologi Sepuluh Nopember, Surabaya, Indonesia 
Table 1: SAW welding parameter

\begin{tabular}{|c|c|c|c|c|c|c|c|}
\hline \multirow[b]{2}{*}{ Layer } & \multirow[b]{2}{*}{ Process } & \multicolumn{2}{|c|}{ Filler metal } & \multicolumn{2}{|l|}{ Current } & \multirow[b]{2}{*}{ Volt range } & \multirow[b]{2}{*}{ Travel speed $(\mathrm{mm} / \mathrm{sec})$} \\
\hline & & Class & Dia. $(\mathrm{mm})$ & Polarity & Ampere & & \\
\hline 1 & SAW & EH12K & 3,2 & DCSP & 300 & $26-30$ & 3.81 \\
\hline 2 & SAW & EH12K & 3,2 & DCSP & 350 & $28-32$ & 3.48 \\
\hline 3 & SAW & EH12K & 3,2 & DCSP & 350 & $28-32$ & 3.48 \\
\hline
\end{tabular}

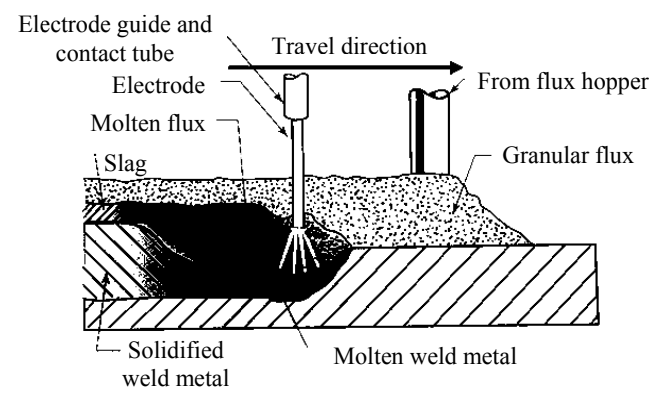

Fig. 1: SAW Jeffur (2012)

- Material specification: ASTM A-36

- Dimensions: $400 \times 150 \times 12 \mathrm{~mm}$

- Welding process: SAW

- Connection type: butt joint single V-Groove

- Welding position: $1 \mathrm{G}$

- Metal filler: A5.17-EH12K (OK Autrod 12.32), Ø $3.2 \mathrm{~mm}$

- Flux: F7A5-EH12K (OK Flux 10.71)

- Flow welding: DC SP and shielding gas

techniques performed by the welder do not have much effect on the quality of welding. For the weakness of this method is because the process is automatic then its use is more limited when compared to welding by hand or semi automatic such as the position of welding is limited only in the horizontal position. An invisible bow due to the flux grain that covers, the incorrect welding determination can thwart the entire welding result (Table 1 and Fig. 1).

Layer 1: In the first layer is also often called root weld or basic welding on the material. Elekrode used in the form of metal filler with type EH12K with $3.2 \mathrm{~mm}$ diameter and menggukan flux in the form of sand with type F7A5. The current used in root weld is $300 \mathrm{~A}$ and the voltage range is $26-30 \mathrm{~V}$. The time taken in the 1 pass weld is $105 \mathrm{sec}$, so that, the welding speed is 3.81 $\mathrm{mm} / \mathrm{sec}$.

Layer 2: The second layer is an electrode or fill area. At this stage the elekrode used is a metal filler with type EH12K with a diameter of $3.2 \mathrm{~mm}$ and menggukan flux in the form of sand with type F7A5. The current used in root weld is $350 \mathrm{~A}$ and a voltage range of $28-32 \mathrm{~V}$. The time taken in the 1 pass weld is $115 \mathrm{sec}$, so that, the welding speed is $3.48 \mathrm{~mm} / \mathrm{sec}$.

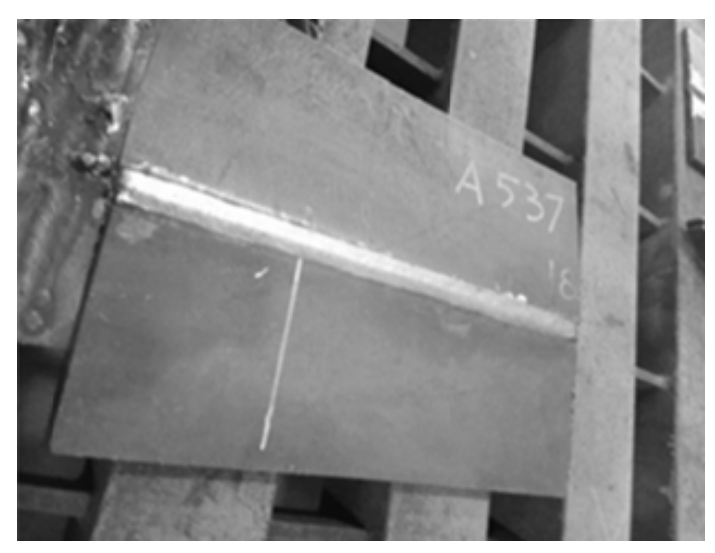

Fig. 2: SAW welding

Layer 3: On the third layer is the upper area of the weld or capping. At this stage the elekrode used is a metal filler with type EH12K with a diameter of $3.2 \mathrm{~mm}$ and menggukan flux in the form of sand with type F7A5. The current used in root weld is $350 \mathrm{~A}$ and a voltage range of $28-32 \mathrm{~V}$. The time taken in the 1 pass weld is $115 \mathrm{sec}$, so that, the welding speed is $3.48 \mathrm{~mm} / \mathrm{sec}$ (Fig. 2).

Flux cored arc welding: Central-core core flux/middle core protective weld is commonly known as FCAW (Flux Cored Arc Welding) welding process is one of the welding process using a metal filled filler arc in the form of electrodes that can be fed continuously with the work plane is usually tubular. FCAW welding is operated semi-automatic or automatic. Applications for semi-automatic FCAW welding are often used in the world of steel structure fabrication. Usually performed on hard welding diaskes, short weld production or welding position out like vertical or overhead. In general, FCAW welding uses semi-automatic operation. According to its usefulness FCAW is classified into two types of variation depending on the protective electrode ie FCAW-ss and FCAW-g. Welding FCAW-ss (Self Shielded Flux Core Arc Welding) is the process of protecting melt weld metal by using gas from the evaporation or reaction of the flux core. While welding FCAW-g protection with dual gas, that is protecting melt weld metal by using own gas also added protective gas that come from outside sistemu. Generally, the gas used is carbon dioxide $\left(\mathrm{CO}_{2}\right)$ as a protective gas although, it can also use other gas mixtures like argon (Fig. 3). 
Table 2: FCAW welding parameter

\begin{tabular}{|c|c|c|c|c|c|c|c|}
\hline \multirow[b]{2}{*}{ Layer } & \multirow[b]{2}{*}{ Process } & \multicolumn{2}{|c|}{ Filler metal } & \multicolumn{2}{|l|}{ Current } & \multirow[b]{2}{*}{ Volt range } & \multirow[b]{2}{*}{ Travel speed $(\mathrm{mm} / \mathrm{sec})$} \\
\hline & & Class & Diameter $(\mathrm{mm})$ & Polarity & Ampere & & \\
\hline 1 & FCAW & E71T-1C & 1,2 & DCSP & 120 & $22-27$ & 2.22 \\
\hline 2 & FCAW & E71T-1C & 1,2 & DCSP & 120 & $22-27$ & 2.45 \\
\hline 3 & FCAW & E71T-1C & 1,2 & DCSP & 120 & $22-27$ & 2.35 \\
\hline
\end{tabular}

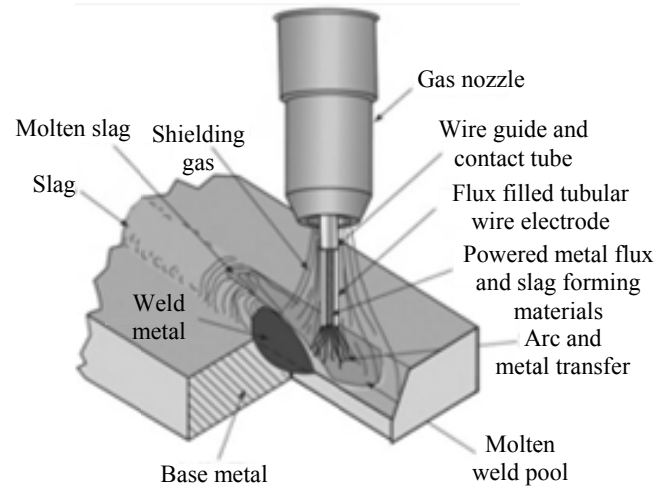

Fig. 3: FCAW Jeffur (2012)

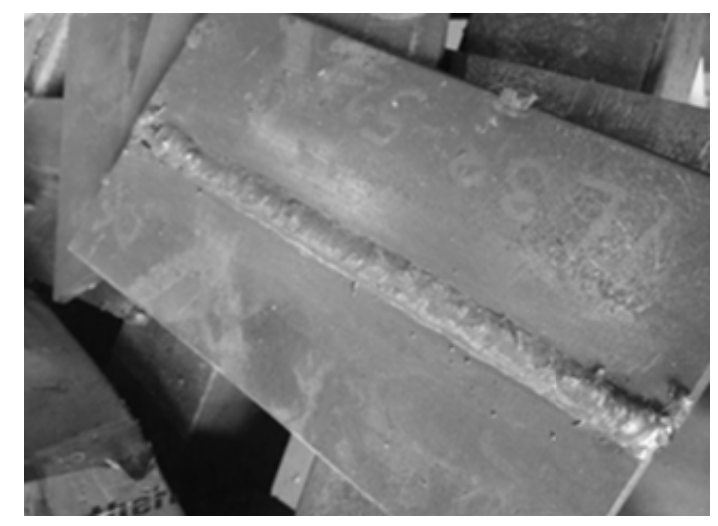

Fig. 4: FCAW welding

- Material specification: ASTM A-36

- Dimensions: $400 \times 150 \times 12 \mathrm{~mm}$

- Welding process: semi automatic FCAW

- Connection type: butt joint single V-Groove

- Welding position: $1 \mathrm{G}$

- Metal filler: A5.20-E71T-1C, Ø $1.2 \mathrm{~mm}$

- Flow welding: DC SP

- Shielding gas: $\mathrm{CO}_{2}$

- Backing: ceramic

Layer 1: In the first layer is also often called root weld or basic welding on the material. Elekrode used is a metal filler with type E71T-1C with a diameter of $1.2 \mathrm{~mm}$ and menggukan $\mathrm{CO}_{2}$ protective gas. The current used in the root weld is $120 \mathrm{~A}$ and the voltage range is $22-27 \mathrm{~V}$. The time taken in welding 1 pass of $180 \mathrm{sec}$, so that, the welding speed of $2.22 \mathrm{~mm} / \mathrm{sec}$ (Table 2 and Fig. 4).
Layer 2: The second layer is an electrode or fill area. At this stage the elekrode used is a metal filler with type E71T-1C with a diameter of $1.2 \mathrm{~mm}$ and menggukan $\mathrm{CO}_{2}$ protective gas. The current used in the root weld is $120 \mathrm{~A}$ and the voltage range is $22-27 \mathrm{~V}$. The time taken in welding 1 pass of $163 \mathrm{sec}$, so that, the welding speed of $2.45 \mathrm{~mm} / \mathrm{sec}$ (ASME BPVC-IX-2013, 2013).

Layer 3: On the third layer is the upper area of the weld or capping. At this stage the elekrode used is a metal filler with type E71T-1C with a diameter of $1.2 \mathrm{~mm}$ and menggukan $\mathrm{CO}_{2}$ protective gas. The current used in the root weld is $120 \mathrm{~A}$ and the voltage range is $22-27 \mathrm{~V}$. The time taken in welding 1 pass of $170 \mathrm{sec}$, so that, the welding speed of $2.35 \mathrm{~mm} / \mathrm{sec}$.

\section{RESULTS AND DISCUSSION}

\section{Analysis data}

Radiographic test: Radiographic tests are conducted to determine whether or not a defect is a specimen that can not be seen by the naked eye. Where this specimen is given radiation rays to detect any defects or not. According to ASME IX, the result is expressed accepted if the radiographic result is no defect along the weld. While the results are rejected if the length of porosity exceeds $20 \%$ of plate thickness. The most commonly used radiographic method for welded joints is direct radiography, i.e., images photographed radiographically directly onto x-ray film sheets. In a radiographic test, as any damage photographed to visualized radiographs, the type of damage can be identified relatively easily. However, since, x-ray films should be placed on the specimen at the rear of the welding area, the film is difficult to use on certain types of welded joints. To enhance the sensitivity of the film, strictly use sensitive florescent paper or metal foil paper sensitive to the film during the radiographic process.

SAW welding is very rare because SAW engine has advantages such as welding areas that have good quality due to fluid covered by flux where the possibility of porosity is very small. Radiographic test results on FCAW welds are declared rejected which means there are defects in the welding results in Fig. 5. The defects contained in FCAW welding results are worm hole or wormhole. This is caused by the gas from outside into the weld and trapped there. In addition porosity is caused by dirty workpieces. 


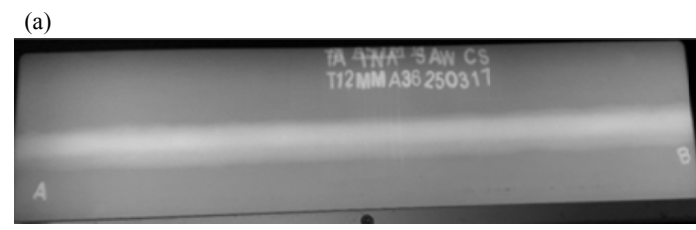

(b)

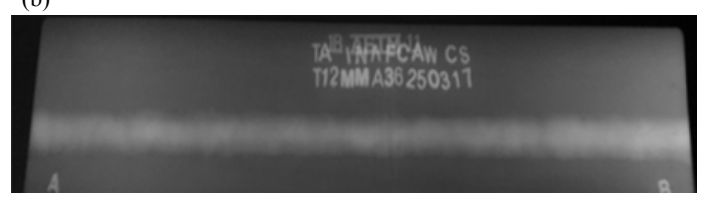

Fig. 5(a-b): Radiografi SAW dan FCAW

Table 3: Summary Kekuatan Tarik

\begin{tabular}{lcc}
\hline Codes & $\begin{array}{c}\text { Tensile strength } \\
(\mathrm{MPa})\end{array}$ & $\begin{array}{c}\text { Ultimate strength } \\
(\mathrm{MPa})\end{array}$ \\
\hline Baja ASTM A36 & 335.0 & 452.00 \\
SAW & 346.3 & 522.07 \\
FCAW & 346.3 & 516.40 \\
\hline
\end{tabular}

Tensile test: The tensile test is the most basic material test in which the cut material is tested by being drawn in the direction of the axial force in order to know how the material reacts to the tensile force and to know the extent to which the material is incremental, the results of this test will get a tug profile of stress-strain diagram. Initially specimens formed according to standards. After that tensile test is done by giving the axial style which will be longer will experience the local deformation and finally break. Thus it produces tensile strength of welds, elastic boundaries, yield points and ductility and explains the stress-strain curve where the maximum tensile stress or Ultimate Tensile Strength (UTS) is the maximum capability of the material in holding the load. The yield point, i.e. where the metal has a long increase without significant load increase. In other words the yield point is the state where the specimen is deformed with minimum load. For materials that do not have a good groove. Here's the formula to do the calculation after the tensile test is done:

$$
\begin{gathered}
\sigma \text { Ultimate }=\frac{\text { F Ultimate }}{A} \mathrm{~N} / \mathrm{mm}^{2} \\
\sigma \text { Yield }=\frac{\text { FYield }}{A} \mathrm{~N} / \mathrm{mm}^{2}
\end{gathered}
$$

Where:

$$
\begin{array}{ll}
\text { A } & \text { : Initial cross section area }\left(\mathrm{mm}^{2}\right) \\
\text { F Ultimate } & \text { : Maximum load (Newton) } \\
\text { F Yield } & \text { : Yield load (Newton) }
\end{array}
$$

This test is conducted to determine the strength and durability of ASTM A36 material to the tensile force given by the load slowly until the material is broken. This test is a basic test in welding to find out how strong the results of welds produced. The ultimate power of SAW welding is $522.07 \mathrm{MPa}$ while the ultimate welding power of FCAW is $516.4 \mathrm{MPa}$ in Table 3. It is like the previous research by Hadi and Eko Sasmiko that the yield of tensile strength between welding SAW and FCAW shows the same result because it shows no significant difference, the difference is $1 \%$.

The tensile strength of the two welds can be passed in accordance with ASME section IX 2013 standard. Where the weld strength value of both welds exceeds the tensile strength of the parent metal. The value of the yield strength of the parent metal weld is $335 \mathrm{MPa}$ and the ultimate powers of $452 \mathrm{MPa}$.

Hardness test: Hardness tests are the most important and most widely used in mechanical tests to determine the properties of metals as well as certain other materials. The hardness of the material is usually assessed for its resistance to permanent (permanent deform) press. generally an identor is pressed on the surface of the metal to be tested with a certain load at a certain time interval and the measurement is obtained from the size and depth of the identor. The main principle of this test is to determine the suitability of materials in a particular application or a particular treatment on an object. The ease of this hardness test is the most common method performed in metal and metallic inspection (Chandler, 1999).

The method used for this final project is Vickers method. One method of hardness testing has the objective of knowing the durability of a material by providing a load using a diamond pyramid identifier with an angle of $136^{\circ}$ between the diamond pyramid surface facing each other with the test material. The reference used is ASTM E 92 (ASTME92-82(1997)e3., 1997). Violence of vickers is expressed in the following formula:

$$
\mathrm{VHN}=\frac{2 \mathrm{P} \sin \left(\frac{\theta}{2}\right)}{\mathrm{d}^{2}}=\frac{1.854 \times \mathrm{P}}{\mathrm{d}^{2}}
$$

$$
\begin{aligned}
& \text { Where: } \\
& \text { VHN : Violence Vickers }\left(\mathrm{Kgf} / \mathrm{mm}^{2}\right) \\
& \mathrm{P}: \text { Load used }(\mathrm{Kgf}) \\
& \mathrm{D}: \text { Average diagonal length }(\mathrm{mm}) \\
& \theta \quad: \text { Angle between opposite diamond surface }=136^{\circ}
\end{aligned}
$$

Hardness testing is done to determine the level of hardness of a material. With this test known ductile or brittle material types. Hardness coincides with some properties of steel materials. The harder the material, the higher the tensile strength (tensile strength), the higher the level of kegetasnya and the lower keuletannya on the contrary the more soft a material the lower the tensile Table 4: Hardness Vickers number 
J. Eng. Applied Sci., 15 (1): 261-266, 2020

\begin{tabular}{lcc}
\hline Welding & HAZ & Weld metal \\
\hline SAW & 172.83 & 217.97 \\
FCAW & 155.73 & 193.20 \\
\hline
\end{tabular}

Table 5: Impact test Vicker number

\begin{tabular}{lcc}
\hline Welding & HAZ & Weld metal \\
\hline FCAW & 1.848 & 1.779 \\
SAW & 1.826 & 0.978 \\
\hline
\end{tabular}

strengthnya, the lower the kegetasannya and increasingly keuletannya. Where violence is directly proportional to strength and hardship and inversely proportional to its tenacity. Violence testing is done at 6 points and every 3 point test area (Table 4).

From Fig. 5 of hardness test result above can be seen the highest hardness value is dominated by SAW welding where in every area hardness value bigger than FCAW. For hardness value at highest $\mathrm{HAZ}$ area that is equal to $172.83 \mathrm{HVN}$ and value kekerasn at weld metal area equal to $217.97 \mathrm{HVN}$. Where the following hardness values are the hardness values of SAW welding. It can be concluded that the hardness value of SAW welding is higher than FCAW welding hardness value. This is influenced by SAW heat input greater than FCAW. Can be seen on the WPS, the average SAW welding input is $2613 \mathrm{~J} / \mathrm{mm}$. Thus causing the widening of the larger HAZ area this makes the value of the hardness increases. This is in accordance with the analysis of Marinda hardness test that the greater the heat input received by the material the resulting hardness value is also greater, the tensile strength is stronger and the material becomes more brittle. Conversely, the smaller the resulting heat input the smaller the hardness value, the smaller the tensile strength and the more resilient material properties.

Impact test: The impact test is a test of a material for knowing the brittleness and by means of a sudden loading of a tested object in a static manner. This test is performed because when a brittle breakdown occurs at low temperatures when the temperature is high and the triaxial state of stress. It can use a fatigue test. However, it will take a long time and expensive. Therefore the impact test is done because it requires faster time and lower cost. A strong test of a notch is a test that measures the resistance of the material to the shock load. The basis of the notch testing is the absorption of potential energy from the swinging pendulum load from a certain height and striking the specimen, so that, the test object is deformed. The notch test is an important consideration in designing buildings which are difficult to quantify and as critical measurements in service life especially for safety and high risk products. This test refers to the ASTM E23 standard. The method that has become the standard for this notch test is 2 that is the notch test of Charpy method and Izod method (Halmshaw, 1995).

The test of this impact is energy in Joules $(J)$ and is processed into a notch toughness value in units of Joule $/ \mathrm{mm}^{2}$. Judging from the comparison graph the SAW notch test scores on the weld metal region are much smaller than FCAW welding. Overall, the impact test results on FCAW welding is relatively constant in each of the reviewed areas compared to the takit test results in SAW welding which has the lowest value in weld metal

region compared to the fusion line and HAZ areas. From the above differences due to the influence of welding process parameters such as heat input which theoretically is very influential on the mechanical test results of a material. The greater the value of the resulting heat input the toughness is smaller. While the value of the heat input generated constant in addition to producing a good weld also also better toughness value too. So, the notch value generated at FCAW welds is better than SAW welding because FCAW welding has a relatively constant heat intake which will not damage the quality and toughness of the material. As previous research conducted by Hadi and Eko Sasmiko that the FCAW welding method has a better ductility value is made possible by the presence of a more stable heat input. Increased heat input will alter the HAZ microstructure and produce hard and brittle specimens resulting in a low toughness score. Conversely, if the heat input tends to be constant, the specimen will maintain its micron structure resulting in a high toughness value (Table 5).

\section{CONCLUSION}

Tensile strength on SAW welding and welding does not have significant difference of about $1 \%$. Tensile strength at welding SAW of $522.07 \mathrm{MPa}$ and tensile strength of FCAW welding is $516.40 \mathrm{MPa}$. The highest hardness is in SAW welding. Weld metal hardness value is $217.97 \mathrm{HVN}$ and HAZ (Heat Affected Zone) is 172.83 . The highest toughness value is in FCAW welding with weld metal value of $1,779 \mathrm{~J} / \mathrm{mm}^{2}$ while in HAZ (Heat Affected Zone) area is $1,848 \mathrm{~J} / \mathrm{mm}^{2}$. FCAW welding has better toughness value than SAW welding. This is due to the relatively stable heat input. The higher the toughness value is the value of tensile strength and violence smaller if the value of small toughness value of tensile strength and greater hardness which means the material is strong and brittle.

\section{REFERENCES}

ASME BPVC-IX-2013, 2013. Welding, Brazing and Fusing Qualifications. The American Society of Mechanical Engineers, New York, USA.,.

ASTM E92-82 (1997)e3, 1997. Standard test method for vickers hardness of metallic materials. ASTM International, West Conshohocken, Pennsylvania, USA. https://www.astm.org/DATABASE.CART/ HISTORICAL/E92- 82R97E3. html

Chandler, H., 1999. Hardness Testing. 2nd Edn., ASM Internasional, USA., ISBN: 9781615032211, Pages: 192. 
Halmshaw, R., 1995. Industrial Radiology: Theory and Practice. 2nd Edn., Chapman and Hall, London, UK., ISBN: 9780412627804, Pages: 303.
Jeffur, L., 2012. Welding: Principles and Applications. 7th Edn., Delmar Cengage Learning, Clifton Park, New York, USA., ISBN-13: 978- 1-1110-3917-2, Pages: 972. 